\title{
Enabling Effective Personalized Learning: Determinants for Knowledge based Web Information Retrieval Systems
}

\author{
Y.D. Jayaweera \\ Ph.D. Student \\ Management and Science \\ University \\ Malaysia
}

\author{
Md. Gapar Md. Johar, \\ Ph.D. \\ Professor Dato' \\ Management and Science \\ University \\ Malaysia
}

\author{
S.N. Perera, Ph.D. \\ Senior Lecturer \\ University of Colombo \\ Department of Mathematics
}

Sri Lanka

\begin{abstract}
In the digitized World, information is entangled in a mesh of unstructured web. Finding and retrieving relevant web resources to suit the user's information requirement is a challenge. Moreover, understanding and adapting to cater to different user information requirements is also an uphill task. To achieve the desired outcome, it is needed to have user accepted technology. Therefore, web information retrieval systems, especially search engines, should be user centered.

Technology Acceptance Model (TAM) provides a basis with which one traces how external variables influence belief, attitude, and intention to use. Two cognitive beliefs are posited by TAM; perceived usefulness and perceived ease of use. This empirical study explores the influence of Users and Environment characteristics on a modern web information retrieval system. This paper analyzes the variables to determine perceptions of usefulness, attitude and preferences leading towards frequent factors to influence typical TAM results.
\end{abstract}

\section{Keywords}

Information Retrieval, Technology Acceptance Model (TAM), Learner Intention, Environment Characteristics

\section{INTRODUCTION}

Today, information, especially in its digital form, is not a scarce resource; information exists in abundance and retrieval time and attention have now become the scarce resource [1]. Information overload is now a recognised problem as users struggle to extract and satisfy their information needs due to increasing quantities of information they need to deal with on a daily basis in a timely manner [2]. Users usually seek information through their favorite search engines to retrieve web resources to satisfy their day to day information needs.

The majority of the Information Retrieval on Web is for informational queries where Users seek for information. According to research findings the highest number of queries were classified as informational $(60 \%)$ where the user seeks information relevant to their topics of interest [3]. Carrying out unsupervised learning on the Web lacks effectiveness due to the fact that the result is too specific; it is not personalized. Further, the sheer scale of available content on the Web makes the finding of right content at the right time extremely difficult. Users are overloaded with Information leaving them dangling in the Web.

Technology Acceptance Model (TAM) is a widely accepted model to help understand and explain user behavior in an information system. There have been a number of research publications which have been used to test the suitability of TAM model and results have been reliable [4][5]. This empirical study tried to understand user behavior in information search on the web and to identify the significant factors that influence successful information retrieval in web search. Further, the study identifies desirable factors in eLearning systems in an effort to improve the knowledge based web information retrieval system.

The remainder of this paper is structured as follows. Section 2 gives an overview of the TAM model and web and information retrieval and their current status. The section ends with the theoretical framework adopted for this empirical study which identifies factors that influence users' effective web information seek behavior. Section 3 presents the research methodology. Section 4 presents the results and analysis. Section 5 discusses the results of the study. Finally section 6 concludes the work with topics for future direction.

\section{LITERATURE REVIEW}

This section outlines the existing background in the field of Web Information Retrieval from a perspective of the learner with emphasis on learning and the application of Technology Acceptance Model (TAM).

\subsection{Web and Information Retrieval}

It is common for people to use Web search engines which are not supported in non-Web retrieval settings for navigational and transactional purposes. It is found that roughly $60 \%$ of the queries were classified as informational, $25 \%$ as resource/transactional and 15\% navigational [3]. According to the findings the highest number of queries were classified as informational where the user seeks information relevant to their topic of interest. Searchers may value entry pages to authoritative sites on a topic and pages with useful topic links about documents containing chunks of relevant text.

Most measures employed in web and general Information Retrieval (IR), rate a results list by summing relevance [6] values previously assigned to individual pages in isolation. This approach has the strong advantage (at least in moderate sized collections) that judgments are re-usable. However, the score assigned to a result list in this way may substantially overestimate the actual value to a searcher.

The techniques adopted for Web search so far are not suited for the information explosion. There is no high level structure available which will best suit learners to explore information in connected fashion. Learners have a vast amount of information at their fingertips. Finding them on demand leaves them frustrated. 


\subsubsection{Problems of Web based Information \\ Retrieval}

Many popular search engines relate keyword to the web resources and no connection is made to the overall concept of the keyword. A set of keywords form a Boolean expression which has no contextualization between the keywords and usually returns too many low quality results [7][8][9]. Users have to navigate each page and extract relevant information to suit their information needs. Furthermore, resource to resource there is no connection. Another problem is low precision and recall of web search engines. Many of the retrieved web resources are not related to the user query which is called low precision, and many of relevant documents considered low have not been retrieved yet [10].

\subsection{Technology Acceptance Model (TAM)}

A well-known model related to technology acceptance and use is the Technology Acceptance Model (TAM) [4]. TAM has proven to be a theoretical model in helping to explain and predict user behavior in different information systems constructs. TAM is considered an influential extension of Theory of Reasoned Action (TRA) [11]. Technology Acceptance Model (TAM) is used to explain why a user accepts or rejects information technology by adapting TRA.

In TAM model, there are two factors; perceived usefulness and perceived ease of use, to determine user's behavioral intentions. Davis, F. (1989) defines perceived usefulness as the prospective user's subjective probability that using a specific application system will enhance his or her job or life performance. Perceived Ease of Use (EOU) can be defined as the degree to which the prospective user expects the target system to be free of effort. TAM provides a basis with which one traces how external variables influence belief, attitude, and intention to use. Two cognitive beliefs are posited by TAM, Perceived Usefulness and Perceived Ease of Use.

According to TAM given in figure 1, one's actual use of a technology system is influenced directly or indirectly by the user's behavioral intentions, attitude, perceived usefulness of the system, and perceived ease of the system. The most commonly reported limitation of TAM is the measurement of usage by relying on respondents' self-reporting and assuming that self-reported usage reflects actual usage.

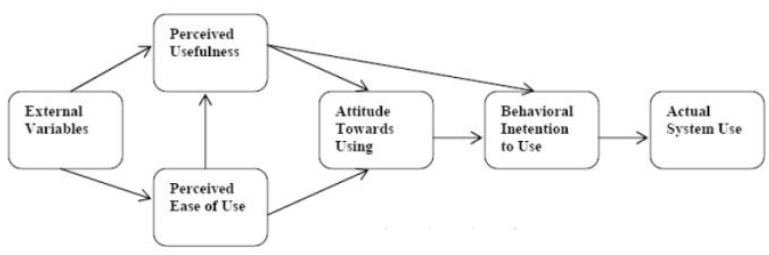

Figure 1: Technology Acceptance Model [4]

\subsubsection{Related Literature in Technology acceptance model}

Technology acceptance model proposed by Davis has been through many changes over years of research. This was done through adding new variables to the existing model. The core of the original model remains intact after years of research and findings.

The Theory of Planned Behavior (TPB) is an extension of the theory of reasoned action, and as in the original theory of reasoned action, the central factor of the theory of planned behaviour is the individual's intention to perform a given behavior [11]. The theory of planned behaviour addresses the issue of behaviours that occur without a person's volitional control. A new model called combined TAM-TPB model which integrated the Technology acceptance model and theory of planned behavior was proposed in a study [12]. TAM2 was proposed a new version of TAM which added new variables to the existing model [5]. Further, another study published the Unified Theory of Acceptance and Use of Technology (UTAUT) Model [13]. The UTAUT model explains user intentions to use an Information System and subsequent usage behavior. The model was developed through a review and consolidation of the constructs of other wellknown models which includes TAM. The original model was extended later; UTAUT2 was proposed in another finding [14]. This study uses TAM to identify User and Environment characteristics for an effective web based information retrieval system by comparing the favorable features of eLearning systems.

\section{RESEARCH METHODOLOGY 3.1 Theoretical Framework}

The framework is presented in figure 2. It represents the TAM adopted for the study with the predictor variables and the outcome variables. It proposes that perceived ease of use and perceived usefulness of technology are predictors of behavioral intentions and actual usage. Perceived ease of use was also considered to influence perceived usefulness of technology. The model also depicts user and environment characteristics as external variables which influence perceived ease of use and perceived usefulness of technology.

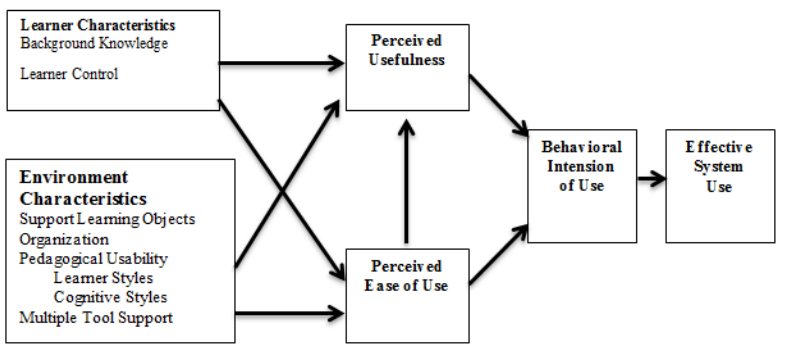

Figure 2: Theoretical Framework with concepts and relationships

The research hypotheses based on figure 2 of the TAM model in the context of the learning system are:

H1: There is a positive relationship between Learner characteristics and learning system's ease of use.

$\mathrm{H}$ 2: There is a positive relationship between Environment characteristics and learning system's ease of use.

H3: There is a positive relationship between Learner characteristics and the learning system's usefulness.

H4: There is a positive relationship between Environment characteristics and learning system's usefulness.

H5: There is a positive relationship between learning system ease of use and learning system usefulness.

H6: There is a positive relationship between learning system usefulness and learners' behavioral intention.

H7: There is a positive relationship between learning system ease of use and learners' behavioral intention.

H8: There is a positive relationship between learners' behavioral intention and effective learning system usage. 


\subsection{Sample}

A survey was conducted on learners from different levels of educational backgrounds. The levels categorize learners as: Professional Certificate, Diploma, Degree and Postgraduate. A convenience sample is drawn from leading private and public Higher Education Institutes in Sri Lanka to evaluate the application of TAM to the learning system. All the respondents were drawn from Information Technology related disciplines and to ensure sample is computer-savvy and well experienced with the systems' operations.

The major aim is to identify their information needs to assist with the learning process. The respondents were drawn from students $(\mathrm{N}=150)$ of different educational background using the eLearning systems on their courses at different stages. Each respondent was asked to fill out an online survey indicating his or her agreement or disagreement with each statement on a 7-point Likert-type scale with the end points being "strongly disagree" and "strongly agree". Scale items appearing on the survey were adapted from previous researches measuring variables in a similar context

Sample demographic information with respect to gender and level of education was also taken for potential control purposes in data analysis. Responses were received from 109 subjects, giving a response rate of around $72 \%(\mathrm{~N}=109)$. Table 1 shows the demographic profile of the respondents.

Table 1: The demographic profile of the respondents

\begin{tabular}{|l|c|c|}
\hline \multicolumn{1}{|c|}{ Variable } & Frequency & Percentage \\
\hline Gender & & \\
Male & 64 & 58.7 \\
Female & 45 & 41.3 \\
\hline Education Level & & \\
Professional & 17 & 15.6 \\
Diploma & 37 & 33.9 \\
Bachelor's Degree & 41 & 37.6 \\
Postgraduate & 14 & 12.8 \\
\hline
\end{tabular}

Among the 109 respondents, $58.7 \%$ were Male learners compared to $41.3 \%$ of their counterpart. Considering the level of Education, $37.6 \%$ respondents had Bachelor's Degree, 33.9\% Diploma certificates, $15.6 \%$ Professional Certificates and $12.8 \%$ Postgraduate certificates.

\subsection{Measures}

In this section reliability and construct validity were evaluated. The reliability analysis was conducted to ensure the internal validity and consistency of the items used for each variable. The measure indicates the extent to which it is without bias. Hair et al. (2010) recommended that Cronbach's alpha values below 0.6 was considered to be poor. The closer Cronbach's alpha is to 1, higher the internal consistency reliability. Table 2 shows the reliability of the measurement scales. Cronbach's alpha reliability scores were all above 0.6 , which is considered to be acceptable [15]. Hence, the results given in table 2 demonstrate that the questionnaire is a reliable measurement instrument.
Table 2: Reliable measurement

\begin{tabular}{|c|c|c|c|}
\hline Variable & Scale & $\begin{array}{c}\text { Cronbach } \\
\text { alpha }\end{array}$ & $\begin{array}{c}\text { Number of } \\
\text { Items }\end{array}$ \\
\hline BK & $\begin{array}{l}\text { Background } \\
\text { Knowledge }\end{array}$ & .632 & 2 \\
\hline $\mathrm{LC}$ & Learner Control & .728 & 7 \\
\hline PEDU & $\begin{array}{l}\text { Pedagogical } \\
\text { Usability }\end{array}$ & .678 & 6 \\
\hline MI & $\begin{array}{l}\text { Multimedia } \\
\text { instruction }\end{array}$ & .725 & 4 \\
\hline PS & $\begin{array}{l}\text { Perceived Ease of } \\
\text { Use }\end{array}$ & .634 & 6 \\
\hline PERU & $\begin{array}{l}\text { Perceived } \\
\text { Usefulness }\end{array}$ & .689 & 3 \\
\hline BI & $\begin{array}{l}\text { Behavioral } \\
\text { Intention }\end{array}$ & .710 & 3 \\
\hline SE & $\begin{array}{l}\text { Effective System } \\
\text { Use }\end{array}$ & .840 & 3 \\
\hline
\end{tabular}

\subsection{Results from Factor analysis}

Table 3 summarizes factor loading and percentage of variance per factor.

Table 3: Factor Loading

\begin{tabular}{|l|c|c|c|c|c|c|c|c|c|c|}
\hline IsRm & 1 & 2 & 3 & 4 & 5 & 6 & 7 & 3 & 9 & 10 \\
\hline BK1 & 0.569 & & & & & & & & & \\
\hline BK2 & 0.569 & & & & & & & & & \\
\hline LC1 & & 0.509 & & & & & & & & \\
\hline LC2 & & 0.316 & & & & & & & & \\
\hline LC3 & & 0.659 & & & & & & & & \\
\hline PEDU1 & & & & 0.506 & & & & & & \\
\hline PEDU2 & & & & 0.671 & & & & & & \\
\hline PEDU3 & & & & 0.539 & & & & & & \\
\hline PEDU5 & & & 0.626 & & & & & & & \\
\hline PEDU6 & & & 0.755 & & & & & & & \\
\hline MI1 & & & & & 0.505 & & & & & \\
\hline MI2 & & & & & 0.710 & & & & & \\
\hline MI3 & & & & & 0.960 & & & & & \\
\hline MI4 & & & & & 0.507 & & & & & \\
\hline PS1 & & & & & & & 0.552 & & & \\
\hline PS2 & & & & & & & 0.713 & & & \\
\hline PS3 & & & & & & & 0.756 & & & \\
\hline PS4 & & & & & & 0.572 & & & & \\
\hline PS5 & & & & & & 0.994 & & & & \\
\hline PS6 & & & & & & 0.509 & & & & \\
\hline PERU1 & & & & & & & & 0.67 & & \\
\hline PERU2 & & & & & & & & 0.67 & & \\
\hline BI1 & & & & & & & & & 0.531 & \\
\hline BI2 & & & & & & & & & 0.506 & \\
\hline BI3 & & & & & & & & & 0.598 & \\
\hline SE1 & & & & & & & & & & 0.973 \\
\hline SE2 & & & & & & & & & & 0.750 \\
\hline SE3 & & & & & & & & & & 0.700 \\
\hline \% VI & 35 & 45 & 22 & 18 & 45 & 28 & 22 & 45 & 55 & 67 \\
\hline
\end{tabular}


Principal axis factoring was used with promax rotation and Kaiser normalization, $\mathrm{N}=109$

All factor loadings given are above 0.50 [16], showing good convergent validity.

\section{RESULTS AND ANALYSIS}

\subsection{Item correlation analysis}

In this section detailed results of the Item correlation analysis is discussed. Table 4 summarizes the correlations.

In correlation analysis given in table 4 , there were moderate levels of correlation between Environment Characteristics and the dependent variables; Perceived Ease of Use and Perceived Usefulness. But the correlation between Learner Characteristics and other dependent variables was very low, which was less than 0.3. Thus, associations between Learner Characteristics and the dependent variables; Perceived Ease of Use and Perceived Usefulness were dropped. Further, there was no evident correlation between Perceived Ease of Use and Perceived Usefulness. The $\mathrm{r}$ value between predictors was less than 0.9. Perhaps, there is no problem of multicolinearity.

There was no significant correlation between participants' gender, education and the other dependent variables namely: the $\mathrm{p}$-value was greater than 0.05 . Therefore, these demographic variables were dropped from further analysis.

\subsection{Results of Hypothesis Testing}

Linear regression analyses were conducted based on 109 completed surveys collected from the study. According to correlation analysis there was a poor relation between Learner Characteristics and the outcome variables. Hence, $\mathrm{H} 1$ and $\mathrm{H} 3$ were not supported. In testing Hypothesis 2 (H2), a regression analysis was performed, with Environment Characteristics as the predictor of Perceived Ease of Use as the outcome variable. Table 5 presents the regression results used to test $\mathrm{H} 2$.

Table 5: Regression results for $\mathrm{H} 2$

\begin{tabular}{|c|c|c|c|c|}
\hline Variable & $\beta$ & $\begin{array}{c}\text { Standard } \\
\text { Error of } \beta\end{array}$ & $\mathrm{p}$ & $\mathrm{R}^{2}$ \\
\hline $\begin{array}{l}\text { Environment } \\
\text { Characteristics }\end{array}$ & .338 & .084 & $\mathrm{P}<0.05$ & .306 \\
\hline
\end{tabular}

Every unit increase in Environment Characteristics, Perceived Ease of Use is expected to be higher by 0.338 units. The predictor is significant at 0.05 level. Thus Perceived Ease of Use depends on Environment Characteristics. The r-squared value is 0.306 which means $30 \%$ of the variation in Perceived Ease of Use can be explained by Environment Characteristics.

Table 4: Correlation between the variables

\begin{tabular}{lcccccc}
\hline \multicolumn{1}{c}{ Variable } & $\begin{array}{c}\text { Learner } \\
\text { Characteristics }\end{array}$ & $\begin{array}{c}\text { Environment } \\
\text { Characteristics }\end{array}$ & $\begin{array}{c}\text { Perceived } \\
\text { Ease of Use }\end{array}$ & $\begin{array}{c}\text { Perceived } \\
\text { Usefulness }\end{array}$ & $\begin{array}{c}\text { Behavioral } \\
\text { Intention }\end{array}$ & $\begin{array}{c}\text { Effective } \\
\text { System Use }\end{array}$ \\
\hline $\begin{array}{l}\text { Learner } \\
\text { Characteristics }\end{array}$ & 1.000 & .388 & .123 & .120 & .209 & .135 \\
$\begin{array}{l}\text { Environment } \\
\text { Characteristics }\end{array}$ & .388 & 1.000 & .306 & .391 & .196 & .198 \\
$\begin{array}{l}\text { Perceived Ease of } \\
\text { Use }\end{array}$ & .123 & .306 & 1.000 & .260 & .314 & .200 \\
$\begin{array}{l}\text { Perceived } \\
\text { Usefulness }\end{array}$ & .120 & .391 & .260 & 1.000 & .467 & .164 \\
$\begin{array}{l}\text { Behavioral } \\
\text { Intention }\end{array}$ & .209 & .196 & .314 & .467 & 1.000 & .580 \\
$\begin{array}{l}\text { Effective System } \\
\text { Use }\end{array}$ & .135 & .198 & .200 & .164 & .580 & 1.000 \\
\hline
\end{tabular}

In testing Hypothesis 4 (H4), a regression analysis was performed, with Environment Characteristics as the predictor of Perceived Usefulness as the outcome variable. Table 6 presents the regression results used to test $\mathrm{H} 4$.

Table 6: Regression results for $\mathrm{H4}$

\begin{tabular}{|c|c|c|c|c|}
\hline \multicolumn{1}{|c|}{ Variable } & $\beta$ & $\begin{array}{c}\text { Standard } \\
\text { Error of } \beta\end{array}$ & $\mathrm{p}$ & $\mathrm{R}^{2}$ \\
\hline $\begin{array}{l}\text { Environment } \\
\text { Characteristics }\end{array}$ & .368 & .098 & $\mathrm{P}<0.05$ & .391 \\
\hline
\end{tabular}

Every unit increase in Environment Characteristics, Perceived Usefulness is expected to be higher by 0.368 units. The predictor is significant at 0.05 level. Thus Perceived Usefulness depends on Environment Characteristics. The rsquared value is 0.391 which means $39 \%$ of the variation in Perceived Usefulness can be explained by Environment Characteristics.

The $r$ value between Perceived Ease of Use and Perceived Usefulness is less than 0.3 . Therefore, the relationship was dropped and Hypothesis 5 (H5) was not supported.

Hypothesis 6 (H6) and Hypothesis 7 (H7) were tested by regressing both perceived ease of use and perceived usefulness on Behavioral Intention towards using the learning system. Table 7 provides the results from the regression analysis for both $\mathrm{H} 6$ and $\mathrm{H} 7$.

Table 7: Regression results for $\mathrm{H6}$ and $\mathrm{H} 7$

\begin{tabular}{|c|c|c|c|c|}
\hline Variable & $\mathrm{B}$ & $\begin{array}{c}\text { Standard } \\
\text { Error of } \beta\end{array}$ & $\mathrm{p}$ & $\mathrm{R}^{2}$ \\
\hline $\begin{array}{c}\text { Perceived ease } \\
\text { of use }\end{array}$ & .416 & .87 & $\mathrm{P}<0.05$ & .508 \\
\hline $\begin{array}{c}\text { Perceived } \\
\text { usefulness }\end{array}$ & .278 & .116 & $\mathrm{P}<0.05$ & \\
\hline
\end{tabular}

As shown in table 7, both perceived ease of use and perceived usefulness have a significant influence on Behavioral Intention towards using the learning system. Every unit increase in perceived ease of use, Behavioral Intention 
towards using the learning system is expected to be higher by 0.416 units keeping the other factors fixed. Similarly, every unit increase in perceived usefulness, Behavioral Intention towards using the learning system is expected to be higher by 0.278 units keeping the other factors fixed. Both predictors are significant at 0.05 level. Thus Behavioral Intention towards using the learning system depends on perceived ease of use and perceived usefulness. The r-squared value is 0.508 which means $50 \%$ of the variation in Perceived Usefulness can be explained by Environment Characteristics. Accordingly, $\mathrm{H} 6$ and $\mathrm{H} 7$ are both supported.

Hypothesis 8 (H8) was tested by regressing both Behavioral Intention towards using the learning system on effective learning system usage. Table 8 provides the results from the regression analysis for $\mathrm{H} 8$.

Table 8: Regression results for $\mathrm{H8}$

\begin{tabular}{|c|c|l|c|c|}
\hline Variable & \multicolumn{1}{|c|}{$\beta$} & \multicolumn{1}{c|}{$\begin{array}{c}\text { Standard } \\
\text { Error of } \beta\end{array}$} & $\mathrm{p}$ & \multicolumn{1}{c|}{$\mathrm{R}^{2}$} \\
\hline $\begin{array}{l}\text { Effective learning } \\
\text { system usage }\end{array}$ & .588 & .080 & $\mathrm{P}<0.05$ & .580 \\
\hline
\end{tabular}

Every unit increase in Behavioral Intention towards using the learning system, Effective learning system usage is expected to be higher by 0.588 units. The predictor is significant at 0.05 level. Thus Effective learning system usage depends on Behavioral Intention towards using the learning system. The r-squared value is 0.58 which means $58 \%$ of the variation in Perceived Usefulness can be explained by Environment Characteristics. Accordingly, H8 is supported.

Table 9 summarizes the results of the hypotheses testing. Accordingly, H1, H3 and $\mathrm{H} 5$ are not supported because the $\mathrm{r}$ value between the constructs is insignificant.

Table 9: Testing of Hypotheses

\begin{tabular}{|c|l|l|}
\hline Hypothesis & Relationship tested & Results \\
\hline H1 & $\begin{array}{l}\text { Learner characteristics and } \\
\text { learning system ease of use }\end{array}$ & $\begin{array}{l}\text { Not } \\
\text { Supported }\end{array}$ \\
\hline H2 & $\begin{array}{l}\text { Environment } \\
\text { characteristics and learning } \\
\text { system ease of use }\end{array}$ & Supported \\
\hline H3 & $\begin{array}{l}\text { Learner characteristics and } \\
\text { learning system usefulness }\end{array}$ & $\begin{array}{l}\text { Not } \\
\text { Supported }\end{array}$ \\
\hline H4 & $\begin{array}{l}\text { Environment } \\
\text { characteristics and learning } \\
\text { system usefulness }\end{array}$ & Supported \\
\hline H5 & $\begin{array}{l}\text { Learning system ease of } \\
\text { use and learning system } \\
\text { usefulness }\end{array}$ & $\begin{array}{l}\text { Not } \\
\text { Supported }\end{array}$ \\
\hline H6 & $\begin{array}{l}\text { Learning system usefulness } \\
\text { and learners' behavioral } \\
\text { intention }\end{array}$ & Supported \\
\hline
\end{tabular}

\begin{tabular}{|l|l|l|}
\hline H7 & $\begin{array}{l}\text { Learning system ease of } \\
\text { use and learners } \\
\text { behavioral intention }\end{array}$ & Supported \\
\hline H8 & $\begin{array}{l}\text { Learners behavioral } \\
\text { intention and effective } \\
\text { learning system usage }\end{array}$ & Supported \\
\hline
\end{tabular}

\section{DISCUSSION}

This empirical study examined TAM using student acceptance of web Information retrieval using search engines in a learning scenario. Overall, TAM was partially supported. Based on data collected from 109 students, the utility of TAM for explaining acceptance of web information retrieval using search engines by students was evaluated. Accordingly, results showed that environment characteristics had an influence on learning system ease of use and learning system usefulness, whereas influence of learner characteristics on learning system ease of use and learning system usefulness was not significant. Since most of the search engines do not count learner's context into consideration may have led to poor association between the two variables. In agreement with Davis (1989) findings there was a significant association between two predictor variables; learning system ease of use and learning system usefulness on learners' behavioral intention. Furthermore, the results also confirmed the association between learners' behavioral intention and effective learning system usage. Contrary to the TAM model, there was no significance between learning system ease of use and learning system usefulness. Even though the search engines provide ease of use the irrelevant search results which get through negatively impact the system usefulness by lowering the precision. This finding highlights the impact of low precision and recall in the search results that search engines deliver. This might reflect limitations of the application of search engines in a learning scenario. The following section further elaborates the problems faced in the web information search.

Figure 3 depicts on average the number of web resources visited to get information online to satisfy learning requirements.

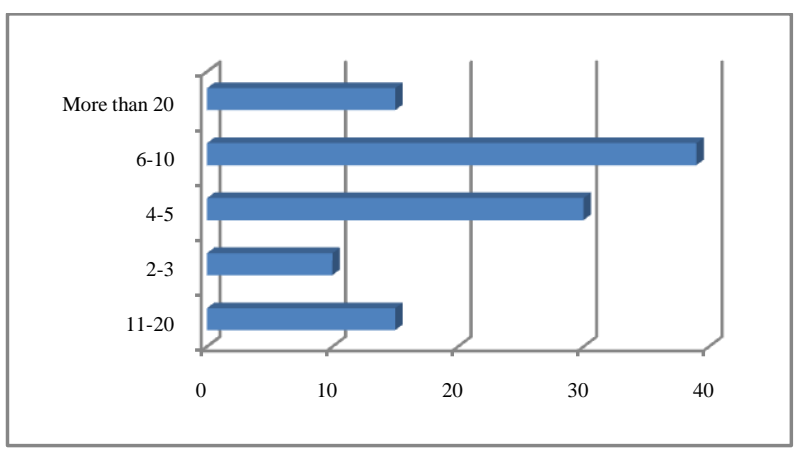

Figure 3: Average number of web resources retrieval to get the required information

According to the findings of 109 respondents, the majority which amounts to $36 \%$ had to view 6-10 web resources to get information they seek. The problem of not finding the relevant resource on demand may be a strong indicator of the weak association between Learning system ease of use and learning system usefulness. Figure 4 shows the difficulties when using a search engine to seek information. 


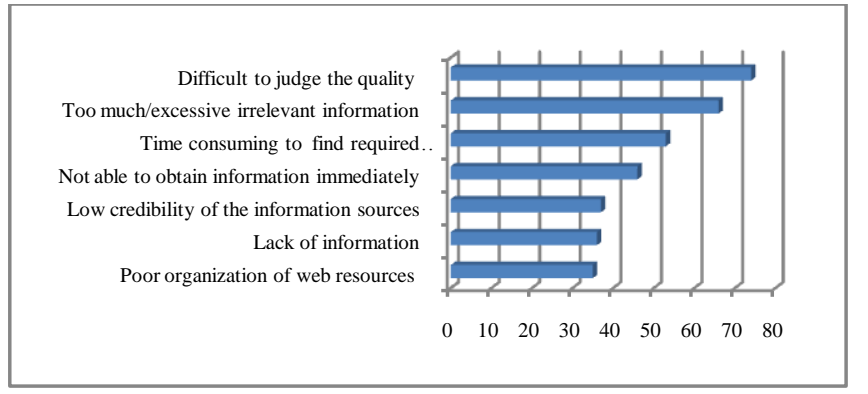

Figure 4: Average number of web resources retrieval to get the required information

According to the findings shown in figure 4 the three main factors which impede information search are: difficulty to judge the quality of the information found on the web, low precision and time consumption. Due to information overload in the web learners find it difficult to retrieve web resources they seek using a search engine in a timely fashion.

The findings also highlight that the web based information retrieval systems should focus more on improving environment characteristics. The result showed that better environment characteristics can lead to improved Learning system ease of use and learning system usefulness. Further, the results of this study showed that TAM can be used to explain the students' acceptance of web search engines.

\section{CONCLUSIONS AND RECOMMENDATIONS}

In this study TAM is used to analyze the level of acceptance using web search engines to retrieve learner information needs. Findings acknowledge the value of the TAM approach as an academic exercise in technology acceptance. In agreement with previous findings [4], there was a significant association between the predictor variables and the outcome variables. However, the association between Perceived Ease of Use and Perceived Usefulness were not significant though it was significant in the original findings. The findings of the study emphasise the importance of leveraging the web resource retrieval systems by taking environmental characteristics into account. Further, the previous studies highlighted learner characteristics too important but findings were not so significant in this study. Arising out of it the modern information retrieval systems should have better content organization, pedagogical usability and multiple tool support to gain learner acceptance by providing a better environment.

One of the limitations of the study concerns the sample which was somewhat skewed, of the findings. The study was conducted using a convenient sample of learners who have average to high computer literacy. The sample covered different knowledge levels of learners who are studying in both state and private institutes in Sri Lanka. Therefore, the findings may not be applicable to learners from other backgrounds. But as reported in the previous research this skewedness may be acceptable [17].

As for the future work, to enhancing future search a prototype will be developed using web of data (semantic web) to extract concepts and show the effectiveness and usefulness of structured data to better relate the content and preferences of learners considering their behavior patterns. The outcomes of this study will be used as the user requirements in developing the prototype which addresses the gap.

\section{REFERENCES}

[1] Simon H. A. (1997). The future of information systems. Annals of Operations Research, 71, 3-14.

[2] Edmunds A. and Morris A. (2000). The problem of information overload in business organisations: a review of the literature. Int. J. of Information Management, 1728.

[3] Rose D. E. and Levinson D. (2004), Understanding user goals in web search, In Proceedings of WWW 2004, pp. 13-19, New York, NY, USA. ACM Press.

[4] Davis F. (1989). Perceived usefulness, perceived ease of use, and user acceptance of information technology, MIS Quarterly 13 (3) 319-340.

[5] Davis F. D. and Venkatesh V. (2004). Toward preprototype user acceptance testing of new information systems: implications for software project management, IEEE Transactions on Engineering Management 51 (1) 31-46.

[6] Järvelin K. and Kekäläinen J. (2002), Cumulated Gainbased Evaluation of IR Techniques.

[7] Page L. and Brin S. (1998). The anatomy of a large-scale hypertext web search engine, Proceeding of the seventh International World Wide Web Conference.

[8] Chakrabarti S., van den Berg M. H., and Dom B. E. (1999). Distributed Hypertext Resource Discovery Through Examples, Proceedings of the 25th VLDB Conference, Edinburgh, Scotland.

[9] Yang Q., Wang H. F., Wen J. R., Zhang G., Lu Y., Lee K. F. and Zhang H. J. (2000). Toward a Next Generation Search engine, Proceedings of the Sixth Pacific Rim Artifact Artificial Intelligence Conference, Melborne, Australia.

[10] Al-Dallal, and Sami A. (2012). Enhancing recall and precision of web search using genetic algorithm, Brunel University, School of Information Systems, Computing and Mathematics.

[11] Ajzen, I. (1991). The theory of planned behavior. Organizational Behavior and Human Decision Processes, 50, 179-211.

[12] Taylor, Shirley and Todd, Peter. (1995). "Assessing IT Usage: The Role of Prior Experience," MIS Quarterly, (19: 4).

[13] Venkatesh, V., Morris, M.G., Davis, G.B., and Davis, F.D. (2003).User acceptance of information technology: Toward a unified view. MIS Quarterly. 27(3); p. 425478.

[14] Venkatesh, V., Thong, J.Y.L., and Xin, X. (2012). "Consumer Acceptance and Use of Information Technology: Extending the Unified Theory of Acceptance and Use of Technology," MIS Quarterly (36:1), 157-178.

[15] Sekaran U., and Bougie R. (2009). Research Methods for Business: A Skill Building Approach, 324-328.

[16] Kaiser, H.F. (1974). An index of factorial simplicity. Psychometrika, 39, 31-36.

[17] Viswanath V. (2012). Consumer Acceptance and Use of Information Technology: Extending the Unified Theory of Acceptance and Use of Technology, MIS Quarterly 36 (1) $157-178$. 